\title{
Professor Arnold L. Demain, a great scientist and founder of a research school. Working with A.L. Demain at MIT.
}

\author{
Juan F. Martín ${ }^{1}$
}

Published online: 28 May 2020

(c) The Author(s), under exclusive licence to the Japan Antibiotics Research Association 2020

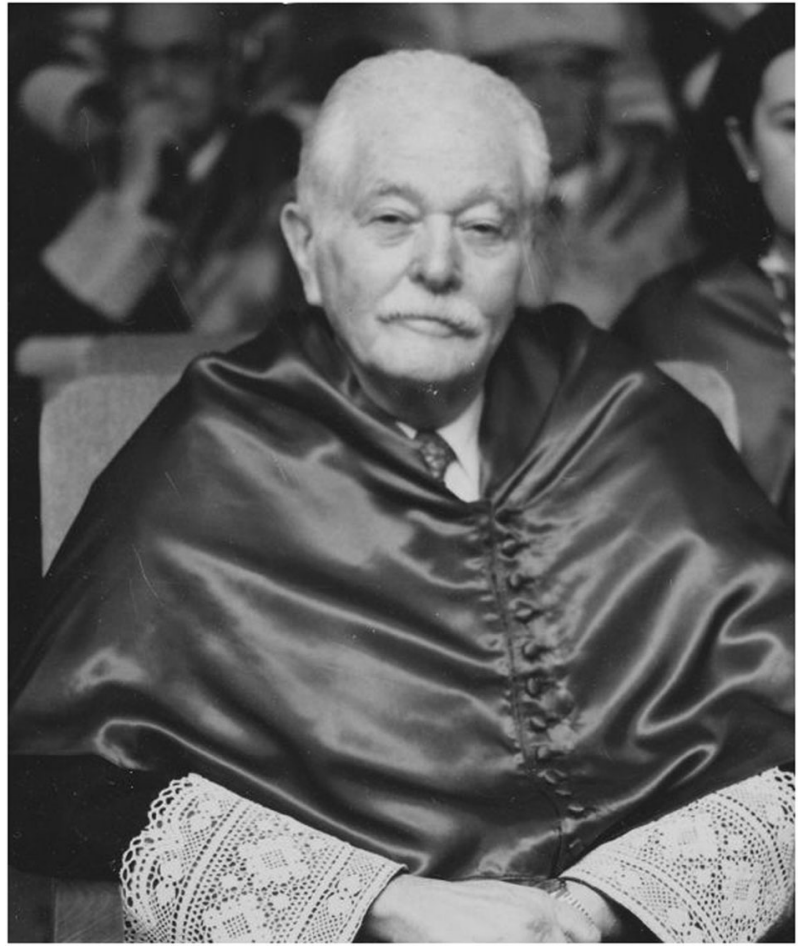

Prof. Demain in academic suit (Dr. Honoris Causa, University of León), in April 1997

Prof. A.L. Demain was born in 1927 in New York and grew up during the Great Depression. After completing in 1954 a $\mathrm{Ph} . \mathrm{D}$. thesis at the Department of Microbiology in the University of California at Davies, Dr. Demain joined Merk Sharp and Dohme and developed an intense research activity in this company during 15 years. Later, in 1969, he was invited to move to MIT as full Professor.

Juan F. Martín

jf.martin@unileon.es

Section of Microbiology, University of León, León 24071, Spain
I met Prof. Demain in 1972, during my 3 years stay in the Waksman Institute of Microbiology, Rutgers University at New Brunswick (NJ) in seminars and in the ASM annual Meetings. Then, in 1974, I joined Dr. Demain laboratory, working actively on the biosynthesis of the antifungal candicidin. Dr. Demain asked me to apply for an NSF Grant that I prepared, and was funded. The NSF support allowed us to develop a new project on the genetics of penicillin biosynthesis that, when I returned to Spain, was continued at MIT by Dr. Cornelius Friedich from Germany. The period of my stay at MIT was a great time since in those years arrived to the MIT laboratory about eight post-docts from Japan, France, Israel, Mexico, Belgium, Germany, and also USA, and a great atmosphere was established under the leadership of Dr. Demain. These good relations made me return several times in summer stays to his laboratory to prepare research articles and reviews.

A distinctive characteristic of Prof. Demain was his wide knowledge of many different types of fermentation processes that was very adequate for my scientific formation. I was impressed by his open character and his ability to interact with the different students and we enjoyed successful lunch seminars, research meetings, and welcome parties for the students that joined the group during those years. He was very supportive for students and post-docts from different countries and with his help I advanced in the research line on the molecular genetics of penicillin biosynthesis that I continued after returning to Spain, first in the Research Council Institute of Microbial Biochemistry (CSIC) at the University of Salamanca, and later as full Professor at the University of León. I proposed to nominate Prof. A.L. Demain as Doctor Honoris Causa by the University of León, and was unanimously approved by the Faculty members. He was invested Doctor Honoris Causa by León University in April 1997.

I am sad that we have lost Dr. Demain but I am proud that I learned from him many research concepts that helped me in my personal development. In addition to his numerous scientific articles (more than 500) the great contribution of Dr. Demain was to create a school of scientist that when 
moved to other Universities in USA or when they returned to their original countries developed research groups in microbial fermentations, and later applied the molecular biology tools to microbial biotechnology.
Juan F. Martín, Ph.D.

Professor of Microbiology

University of León 